\title{
PENGEMBANGAN SMARTCAM AUTO MOTION DETECT DAN SHORT MESSAGE SERVICE (SMS) ALERT
}

\author{
Ade Bastian $^{1}$, Dony Susandi ${ }^{2}$ \\ Universitas Majalengka ${ }^{1}$, Universitas Majalengka ${ }^{2}$ \\ Jl. Universitas Majalengka No.1 Majalengka ${ }^{1}$, Jl. Universitas Majalengka No.1 Majalengka ${ }^{2}$ \\ adb@ft.unma.ac.id ${ }^{1}$,dys@ft.unma.ac.id ${ }^{2}$
}

\begin{abstract}
Abstrak
Perkembangan kehidupan modern berpengaruh terhadap meningkatnya aktivitas manusia yang lebih sering meninggalkan rumah. Kondisi tersebut menimbulkan atau mengundang tindak kejahatan.Dalam dunia Information Technology (IT) segala upaya dilakukan dengan membuat berbagai macam eksperimen, guna membuat suatu sistem yang baru dan semakin mempermudah kerja sistem tersebut. Diantaranya ada suatu sistem pemantau atau monitoring system menggunakan kamera.
\end{abstract}

Sistem Pemantau adalah suatu sistem yang dapat mengawasi segala aktivitas atau kegiatan yang terjadi pada suatu ruangan atau daerah tertentu yang dianggap penting untuk dijaga keamanannya, sehingga dalam penelitian ini dibuataplikasi pengembangansmartcamberbasis auto motion detectdan Sms Alertdengan tujuan untuk memanfaatkan image dan video capturing agar bisa mengontrol keadaan rumah tanpa harus selalu ada di dalam rumah. Aplikasi smartcam dibangun menggunakan perangkat lunak sistem operasi windows 7 ultimatedan bahasa pemrograman Visual Basic.Net 2010.

Hasil penelitian ini adalah aplikasi smartcam berbasis auto motion detect dan sms agar dapat menjaga keamanan rumah saat pemilik sedang tidak berada di tempat serta mengantisipasi dengan cara mengetahui tindak kejahatan lebih dini.

Kata Kunci:Smartcam, Auto Motion Detect, SMS Alert

\begin{abstract}
Modern life is affecting an increasing human activity more often leave the house. These conditions pose or invite crime. In the world of Information Technology ( IT ) every effort was made to create a wide range of experiments, in order to create a new
\end{abstract}

system and further simplify the system works. Among them there is a monitoring system or monitoring system using a camera .

Monitoring System is a system that can oversee all activities or events that occur in a particular room or area that is considered essential to safeguard, so in this study were made based application development SmartCam auto detect movement and SMS Alert with the aim to utilize image and video capturing in order to control the state of the house without having to always be in the house - SmartCam applications built using the software windows 7 operating system and programming language Visual Basic Net 2010.

The aim of this research is to build the SmartCam applications to detect motion and sending the alert through sms while the owner was not in place and anticipate crime by identifying it early .

Keywords: Smartcam, Auto Motion Detect, SMS Alert

\section{Pendahuluan}

Dalam dunia Information Technology (IT) segala upaya dilakukan dengan membuat berbagai macam eksperimen, guna membuat suatu sistem yang baru dan semakin mempermudah kerja sistem tersebut. Diantaranya ada suatu sistem pemantau atau monitoring system menggunakan kamera. Kebanyakan untuk kebutuhan Surveillance atau video security yang dilakukan pada Closed Circuit Television (CCTV), adalah dengan menggunakan camera analog dan VCR atau Video Cassette Recorders serta kabel coaxial. Saat sensor dengan menggunakan CCD (Charged Coupled Device) masuk, hal ini dimungkinkan untuk mengupload gambar dengan format digital. Namun, walaupun sepertinya hal tersebut membawa industri video security ke masa generasi digital, tetapi gambar yang 
diupload tetap saja menggunakan kabel analog ke VCRKegiatan-kegiatan yang ditangkap oleh kamera tersebut dapat disimpan di dalam perangkat penyimpanan seperti harddisk pada komputer atau media penyimpanan file yang dapat diakses dari internet (cloud storage).[Prihatmoko, 2015]

Sistem pengawasan video yang masih tradisional membutuhkan ruang memori yang sangat besar. Kamera merekam dengan kebutuhan ruang penyimpanan yang besar sehingga video yang terekam dan dapat disimpan berdurasi pendek. Kamera dapat mengambil screenshot dari objek yang bergerak secara real time pada memori. Algoritma deteksi gerak membedakan gerak dan pencahayaan. Algoritma deteksi gerakan mempertimbangkan informasi yaitu berupa gambar gerak di suatu tempat.[Suradkar, 2015]

Metode gerak secara umum dikategorikan yaitu diantaranyaBackground Subtraction, Temporal Differencing and flow based. Deteksi gerak objek dalam video adalah tahap dasar dalam sistem pengawasan. Kegunaan streaming video pada foreground dan background, selain fokus pada analisis aktifitas, juga pada pixel foreground. File video tanpa kompresi memerlukan ruang memori yang besar. Kompresi gambar dengan tujuan untuk efisiensi ruang memori dengan pengurangan jumlah byte dan redudansi gambar. Gambar disimpan dengan format BMP, TIFF, GIF dan JPEG. [Deepika, 2014]

Untuk mengontrol sistem pemantauan rumah ini diperlukan suatu perangkat lunak yang digunakan untuk mengatur nomor handphone dan alamat email sebagai penerima pesan. Dan dengan memanfaatkan Image dan Video Capturing, kita dapat menyimpan gambar dan video tersebut kedalam komputer dan media cloud storage.

Perangkat ponsel dikembangkan. Salah satu fasilitas yang disediakan ponsel adalah untuk pengiriman pesan singkat atau disebut Short Message Service (SMS). Diluar negeri pemanfaatan SMS untuk mengirimi pesan rahasia. Di Inggris, perusahaan Staellium UK mengeluarkan layanan "stealth text" yang dapat digunakan untuk mengirimi pesan dengan aman, yaitu dengan menghapus pesan secara otomatis atau yang dikenal dengan nama self-destruct text message. [Yunus, 2015]

Hasil deteksi dari smartcam dalam penelitian ini akan diteruskan pesannya melalui fasilitas SMS pada ponsel.

\section{KaJian PUSTaka}

\section{II.1 Auto Motion Detect}

Deteksi gerakan secara sederhana dapat dilakukan dengan mencari beda antara 2 buah citra yang berurutan pada hasil pencitraan menggunakan kamera video digital. Ada berbagai macam metode untuk membandingkan dua buah gambar. Metode yang sederhana dan prosesnya tidak terlalu berat yaitu dengan mencari nilai perbedaan pixel tertinggi dan membandingkannya dengan suatu nilai batas. Jika nilai perbedaan lebih tinggi dari nilai batas maka disimpulkan terdapat perbedaan pada kedua gambar tersebut. Agar rentang perbedaan pixel tidak terlalu jauh maka sebaiknya dilakukan greyscale terlebih dahulu, yaitu dengan mengambil nilai rata - rata komponen RGB. Jika terdapat 2 buah gambar, gambar 1 dan gambar 2 masing - masing merupakan nilai piksel gambar acuan dan gambar yang akan dibandingkan, sehingga mendapatkan nilai perbedaan piksel tertinggi, dan nilai batas yang telah ditetapkan, maka jika nilai batas lebih besar beda pixel berarti terdapat perbedaan pada kedua gambar. Nilai batas digunakan untuk mentoleransi nilai perbedaan yang dianggap terlalu kecil.[Firdausy, 2008]

Pencarian perbedaan antara 2 buah citra atau gambar yang berurutan pada hasil pencitraan menggunakan kamera video digital adalah prinsip sederhana deteksi gerakan. Operator yang dapat digunakan adalah AND NOT. Operator AND NOT membandingkan previous image dengan actual image.[Firdausy, 2008]

Persamaan untuk deteksi gerak yaitu :

$\mathrm{z}=\mathrm{x}$ AND NOT $\mathrm{y}$

Dengan rincian :

$\mathrm{z}=$ output

$\mathrm{x}=$ previous image

$\mathrm{y}=$ actual image

Tabel kebenaran untuk operasi AND NOT dapat dilihat pada Tabel 1.

Gerakan terdeteksi jika fraksi jumlah pixel yang bernilai 1 lebih dari atau sama dengan batas ambang, atau bisa ditulis seperti pada persamaan 2 . 
Dengan :

Jumlah Piksel = jumlah piksel yang bernilai 1

Jumlah Total Piksel $=$ jumlah piksel keseluruhan dalam frame

Batas Ambang = ambang yang telah ditentukan

Tabel 1. Tabel Kebenaran

\begin{tabular}{|c|c|c|}
\hline \multicolumn{2}{|c|}{ Input } & Output \\
\hline $\mathbf{x}$ & $\mathbf{y}$ & $\mathbf{Z}$ \\
\hline 0 & 0 & 0 \\
\hline 0 & 1 & 0 \\
\hline 1 & 0 & 1 \\
\hline 1 & 1 & 0 \\
\hline
\end{tabular}

Sistem perekaman aktifitas di depan kamera dengan perekaman hanya pada saat ada gerakan merupakan konsep utama Auto Motion Detect. Langkah-langkah pengujian deteksi gerak yaitu pertama kamera dipasang pada sebuah ruanga yang diasumsikan mempunyai pencahayaan yang tetap. Kamera dihubungkan ke komputer agar kamera bisa aktif. Aktifkan program pendeteksi gerakan yang telah dikonfigurasi. Berikan sebuah aksi yaitu gerakan yang berada di dalam jangkauankamera untuk mencoba apakah sistem dapat bekerja, gerakan bisa berupa benda atau orang yang bergerak.[Prihatmoko, 2015]

\section{II.2 Short Message Service}

SMS adalah layanan untuk mengirim dan menerima pesan tertulis (teks) dari maupun ke perangkat bergerak (mobile device). SMS merupakan salah satu fitur Global Standart for Mobile (GSM) yang dikembangkan dan distandarisasi oleh European Telecomunication Standards Institude (ETSI) pada tahun 1991 yang kini dikenal dengan GSM dengan SMS sebagai salah satu layanannya. Karakteristik SMS secara umum antara lain :

1. Prinsip kerja $S M S$ adalah bahwa setiap jaringan mempunyai suatu Service Center (SC). Pesan tidak langsung dikirim ke tujuan, melainkan disimpan dahulu di SC. Suatu SC menjadi penghubung antara Public Land Mobile Network $(P L M N)$ dengan berbagai sistem lainnya seperti surat elektronik, faksimil, atau suatu penyedia layanan (Content Provider).

2. Transmisi SMS dapat terjadi meskipun Mobile Servise (MS) sedang melakukan komunikasi dengan $M S$ lain. Hal ini disebabkan kanal radio untuk transmisi suara telah ditentukan selama pemanggilan berlangsung, sedangkan SMS merambat pada kanal radio dengan memanfaatkan jalur sinyal.

3. Pengiriman SMS yang menggunakan jalur sinyal memiliki dua tipe yaitu SMSPoint to Point (pengiriman $S M S$ hanya dari suatu $M S$ ke $M S$ lain) dan SMSBroadcast/Point to Multipoint (pengiriman $S M S$ ke beberapa SMS secara bersamaan).

4. Setiap pesan yang berhasil dikirimkan oleh telepon seluler makaSC akan mengirimkan laporan keberhasilan atau kegagalan pada $M S$ tersebut.

5. Jaringan sistem GSM memiliki mekanisme penampungan sementara di Mobile Service Switching center (MSC). Ketika MS berada di luarcakupan area atau gagal menerima pesan karena memori $M S$ telah penuh, maka $M S C$ akan mengirimkan pesan yang ditampung tadi setelah $M S$ berada dalam jangkauan atau memori $M S$ ada yang kosong.[Kusumaningrum, 2009]

\section{3 Perancangan Smartcam Auto MOTION DETECT DAN SMS ALERT}

Berikut adalah rancangan arsitektur perangkat lunak yang diperlukan sistem yang akan dibangun. Arsitektur sistem dalam penelitian ini dapat dilihat pada gambar 1 .

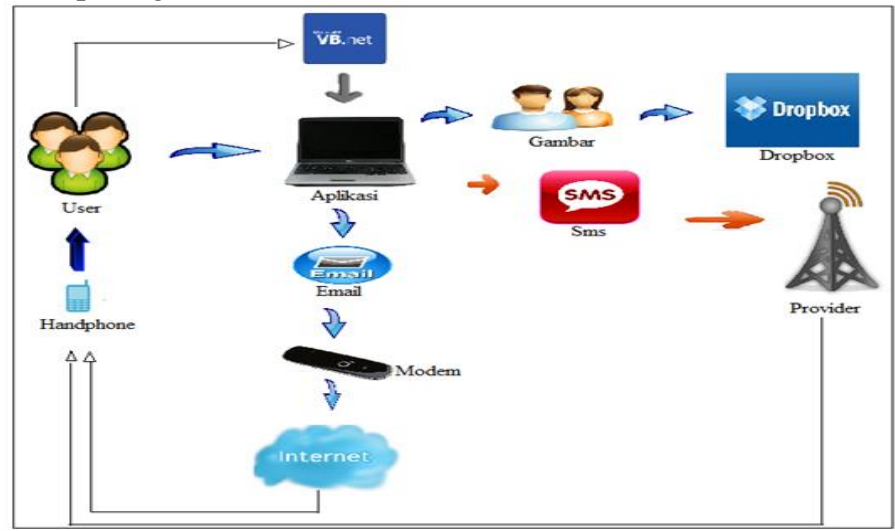

Gambar 1.Arsitektur Perangkat Lunak
Ade Bastian, Dony Susandi

Jurnal Ilmiah Teknologi Informasi Terapan

Volume IV, No 2, 30 April 2018 
Cara kerja sistem Auto Motion Detect yaitu, ketika pengaturan auto detect motion diaktifkan maka ketika terjadi gerakan sistem akan menangkap dan atau merekam pergerakan gambar. Selain itu ketika pengaturan SMS, Email, dan Dropbox diaktifkan maka ketika terjadi gerakan, sistem akan secara otomatis mengirimkan peringatan melalui SMS ataupun Email, dan menyimpan gambar dan video ke dalam dropboxuntuk memberikan informasi keadaan rumah.

\section{Perancangan Sistem}

Sistem Perancangan sistem merupakan tahapan untuk melakukan proses merancang sistem yang akan dibuat agar sesuai dengan yang diharapkan dan hasil sistem yang telah selesai dapat bermanfaat untuk pengguna sistem tersebut. Gambar 2 merupakan perancangan use case diagram pada aplikasi smartcam adalah sebagai berikut:

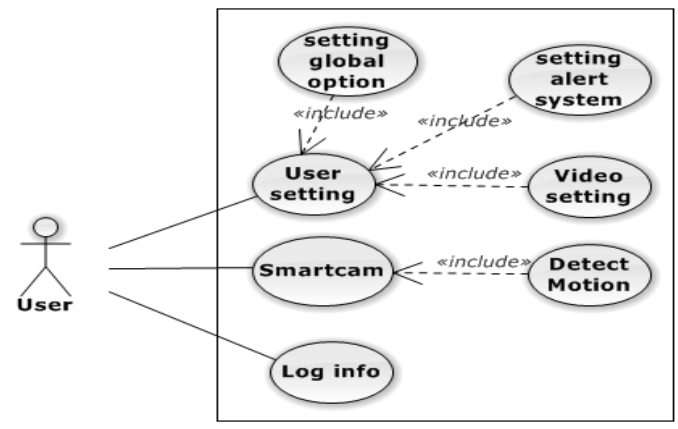

Gambar 2. Use Case Diagram SmartCam

Sistem Statechart diagram dimulai dari melakukan setting path, motion detect dan format, setelah selesai melakukan setting maka akan disimpan. Setting selesai dilakukan, maka selanjutnya membuka aplikasi smartcam akan menyimpan data berupa foto dan video. Bila memilih tombol play maka aktifkan detect motion. Detect motion akan mendeteksi gambar yang nantinya akan disimpan pada dropbox. Kemudian akan mengirimkan alert melalui sms dan email.

Gambar 3 merupakan diagram state untuk perancangan smartcam auto motion detect :

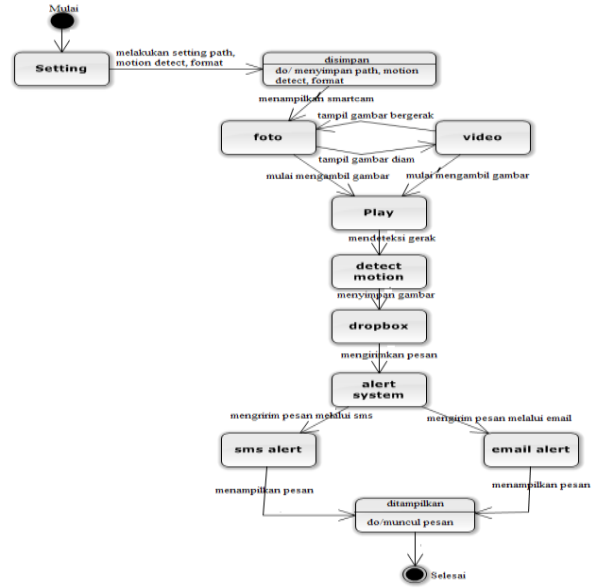

Gambar 3. State Chart Diagram SmartCam

Statechart diagram dimulai dari melakukan setting path, motion detect dan format, setelah selesai melakukan setting maka akan disimpan. Setting selesai dilakukan, maka selanjutnya membuka aplikasi smartcam akan menyimpan data berupa foto dan video. Bila memilih tombol play maka aktifkan detect motion. Detect motion akan mendeteksi gambar yang nantinya akan disimpan pada dropbox. Kemudian akan mengirimkan alert melalui sms dan email.

Class diagram pada gambar 4 mempunyai tiga kelas yang terdiri class user dengan atribut nomor $\mathrm{hp}$, alamat email, dan memiliki operasi terima sms, terima email dan melakukan setting. Class setting dengan atribut path, motion detect, format, dropbox folder, email alert, sms alert dan memiliki operasi simpan dan keluar. Classsmartcam dengan atribut detect motion, auto picture, auto video, sms alert, emil alert dan dropbox dengan operasi save dan cancel. 


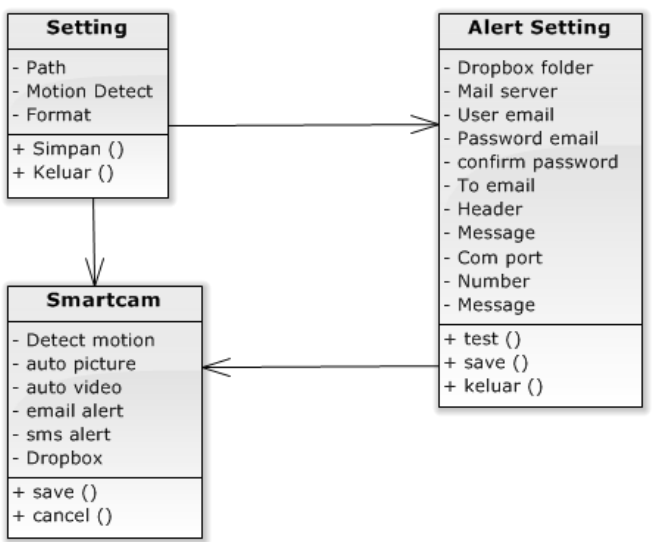

Gambar 4. Class Diagram Smartcam

\section{IMPLEMENTASI}

Tampilan 'Menu Utama' merupakan halaman pertama ketika aplikasi Smartcam dijalankan. Dalam halaman ini terdapat beberapa tombol, menu, informasi, menu check, satu layar besar, dan tiga layar kecil.

Tombol-tombol tersebut antara lain tombol 'Play', tombol 'Stop', tombol 'Capture', dan tombol 'Record'. Tombol 'Play' berfungsi untuk memulai aplikasi sehingga terhubung dengan driver kamera dalam komputer. Tombol 'Stop' berfungsi menghentikan aplikasi sehingga sistem tidak terhubung lagi dengan driver kamera komputer. Tombol 'Capture' berfungsi untuk menangkap gambar. Sedangkan tombol 'Record' berfungsi untuk merekam video.

Menu yang ditampilkan pada halaman 'Menu Utama' tersebut antara lain menu 'Global Setting', 'Alert System', 'Video Resolution', 'Video Compression', 'Log Info', dan menu 'Exit'. Menu 'Global Setting' berfungsi untuk menyimpan pengaturan alamat direktori penyimpanan gambar dan video, pengaturan Motion Detect, dan pengaturan format gambar dan video. Menu 'Alert System' berfungsi untuk menyimpan pengaturan alamat folder dropbox, pengaturan Email Alert, dan pengaturan SMS Alert. Menu 'Video Resolution' berfungsi untuk meyimpan pengaturan resolusi video. Menu 'Video Compression' berfungsi untuk menyimpan pengaturan kompresi video. Menu 'Exit' berfungsi untuk keluar dari aplikasi.
Menu check yang terdapat pada halaman 'Menu Utama' ini meliputi menu 'Detect Motion', 'Auto Capture', 'Auto Record', 'SMS Alert', 'Email Alert', dan menu 'Dropbox'. Menu 'Detect Motion' jika dipilih akan berfungsi untuk mendeteksi gerakan secara otomatis. Menu 'Auto Capture' jika dipilih maka sistem akan menangkap dan menyimpan gambar secara otomatis. Menu 'Auto Record' jika dipilih maka sistem akan merekam dan menyimpan video secara otomatis. Menu 'SMS Alert' jika dipilih berfungsi untuk mengirimkan pesan $S M S$ ke nomor tujuan ketika terjadi gerakan. Menu 'Email Alert' jika dipilih berfungsi untuk mengirimkan pesan ke alamat email tujuan ketika terjadi gerakan. Menu 'Dropbox' jika dipilih berfungsi untuk mengirimkan gambar secara otomatis ke dalam cloud storage jika terjadi gerakan.

Layar besar pada halaman 'Menu Utama' ini berfungsi untuk menampilkan gambar yang tertangkap oleh kamera. Sedangkan tiga layar kecil berfungsi untuk menampilkan preview gambar yang telah disimpan oleh sistem.

Berikut ini beberapa tampilan aplikasi SmartCam dan SMS Alert :

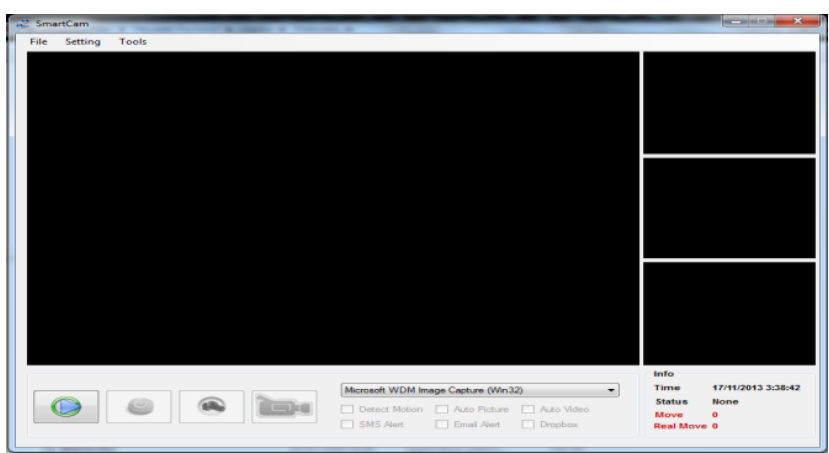

Gambar 5. Tampilan Menu Utama

Tampilan menu Setting 'Alert System' merupakan halaman pengaturan yang berisi pengaturan path penyimpanan cloud storage dropbox, pengaturan Email Alert, dan pengaturan SMS Alert. Pengaturan Email Alert meliputi pengaturan SMTP Server, Username dan pasword email pengirim, alamat email tujuan, subjek email, dan isi pesan. Pengaturan SMS Alert meliputi pengaturan COM Port, nomor tujuan, dan isi pesan. 


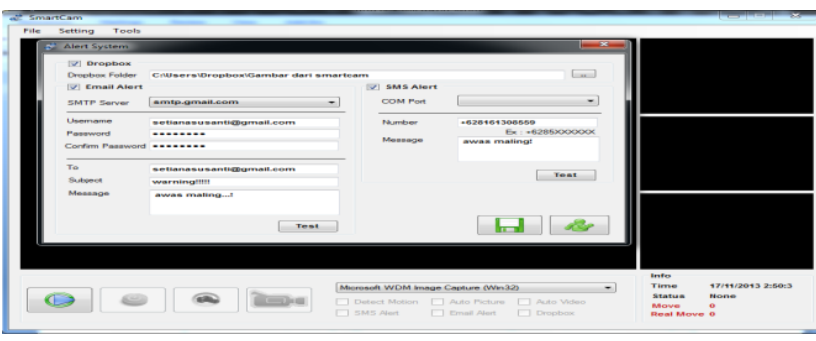

Gambar 6. Tampilan Menu Setting Alert System

Halaman Pengaturan 'Video Resolution' merupakan halaman pengaturan yang berisi pengaturan resolusi video, kedalaman pixel, dan ukuran video. Tampilan menu pengaturah video resolution dapat dilihat pada gambar 7 dibawah ini :

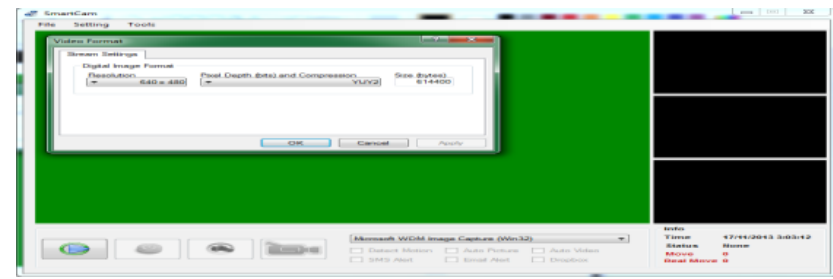

\section{Gambar 7.Tampilan Menu Pengaturan}

Video Resolution

Menu Pengaturan 'Video Compression' merupakan halaman pengaturan yang berisi pengaturan jenis kompresi video. Gambar 8 adalah Halaman Pengaturan Video Compression seperti berikut :

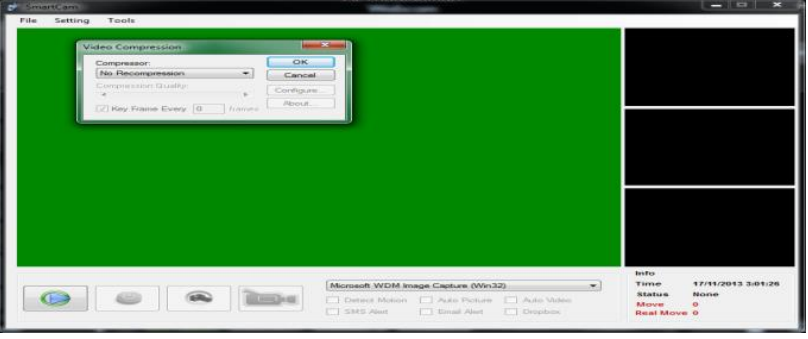

Gambar 8. Tampilan Menu Pengaturan Video Compression

\section{KESIMPULAN DAN SARAN}

\section{VI.1 Kesimpulan}

Berikut Berdasarkan hasil pembahasan diperoleh beberapa kesimpulan yang dapat diambil dalam pembangunan sistem ini adalah sebagai berikut:

1. Aplikasi smartcam ini apabila sensor kamera terpicu dengan gerakan maka kamera akan mengambil gambar tersebut.

2. Aplikasi smartcam berbasis auto motion detect ini secara otomatis mengambil, merekam dan menyimpan gambar ketika ada pergerakan dan juga mengirimkan alert melalui sms dan email pemilik rumah.

3. Aplikasi smartcam berbasis auto motion detect dan smsdapat menjaga keamanan rumah saat pemilik sedang tidak berada di tempat serta mengantisipasi dengan cara mengetahui tindak kejahatan lebih dini.

\section{VI.2 Saran}

Berdasarkan hasil penelitian, maka ada beberapa pandangan peneliti yang sekiranya dapat diangkat sebagai saran adalah:

1. Untuk pengembangan smartcam selanjutnya, sebaiknya gambar yang tertangkap oleh kamera dapat dikirimkan melalui email dan mms.

2. Untuk pengembangan smartcam selanjutnya juga agar menggunakan kamera eksternal yang berkualitas baik, hal ini agar tidak mengurangi kualitas gambar yang tercapture.

\section{DAFTARPUSTAKA}

Deepika, T. and Dr. P. Srinivasa Babu. (2014). Motion Detection In Real-Time Video Surveillance With Movement Frame Capture And Auto Record. International Journal of Innovation Research in Science, Engineering and Technology, Volume 3 Special Issue 1, January.

Kartika, Firdausy, Daryono dan Anton Yudhana. (2008). Webcam Untuk Sistem Pemantauan Menggunakan Metode Deteksi Gerakan.Seminar Nasional Aplikasi Teknologi Informasi. Yogyakarta.

Kusumaningrum, Dyah Ayu. (2009). Analisis dan Perancangan Aplikasi Layanan Informasi 
Berbasis SMS Gateway di PT. Geovisi Mitratama. Universitas Negeri Yogyakarta.

Prihatmoko, Dias. (2015). Pengertian Det. Jurnal DISPROTEK Volume 6 No. 1 Januari.

Suradkar, Harsal, Aniket Kolte, Shreenath Jamdade and Sailee Gokhale. (2015). Automatic Surveillance Using Motion Detecttion. International Journal of Engineering Research and General Science, Volume 3, Issue 2, March-April.

Yunus, Riza M., Harun Sujadi, Karnia. (2015). Sistem Keamanan Pesan Dengan Algoritma Rivest Code 6 (RC-6) Menggunakan Java Pada Smartphone Berbasis Android. Jurnal JENSITEC Vol. 02 No. 01 November. 